\title{
ANALISA PENERAPAN APLIKASI PENJUALAN DAN SERVICE KOMPUTER PADA CV JAYA CITRA MADANI DENGAN METODE TECHNOLOGY ACCEPTABLE MODEL (TAM)
}

\author{
Alief Rizky Dharmawan ${ }^{1)}$, Sri Hariyati Fitriasih ${ }^{2)}$,Tri Irawati ${ }^{3)}$ \\ ${ }^{1)}$ Program Studi Sistem Informasi, STMIK Sinar Nusantara Surakarta \\ ${ }^{2)}$ Program Studi Manajemen Informatika, STMIK Sinar Nusantara Surakarta \\ ${ }^{3)}$ Program Studi Komputerisasi Akuntansi, STMIK Sinar Nusantara Surakarta \\ ${ }^{1)}$ Alief_Rizky@gmail.com, ${ }^{2)}$ fitriasih@ gmail.com, ${ }^{3)}$ triirawati1974@gmail.com
}

\begin{abstract}
CV Jaya Citra Madani is one of the businesses engaged in services of computer service and computer spare parts sales. Currently there is no standard measuring tool to measure the application of sales. This study aims to apply the Technology Acceptable Model (TAM) method measures the use of sales applications especially on the user interface program and ease of use of the application.

The result that the interface design and user behavior had an effect on the real condition of the users with the respective values of 0,644 and 0,988. While the use and attitude have no effect on the real condition of users with the respective values of -0,002 and $-0,444$.
\end{abstract}

Keywords: CV Jaya Citra Madani, Information System, Acceptable Model Technology.

\section{PENDAHULUAN}

Perkembangan teknologi informasi beberapa tahun belakangan ini berkembang dengan kecepatan yang sangat tinggi, sehingga dengan perkembangan ini telah mengubah paradigma masyarakat dalam mencari dan mendapatkan informasi yang tidak lagi terbatas pada informasi seperti surat kabar, audio visual dan elektronik, tetapi juga sumber-sumber informasi lainnya yang salah satu diantaranya melalui sistem informasi dan teknologi.

CV Jaya Citra Madani adalah salah satu bidang usaha yang bergerak di bidang jasa, jasa yang dijalankan oleh CV Jaya Citra Madani adalah service komputer dan penjualan sparepart komputer. Saat ini belum ada alat ukur yang baku untuk mengukur penerapan aplikasi penjualan terhadap pengguaan aplikasi yang digunakan. Penelitian ini bertujuan untuk mencoba menerapkan Metode Technology Acceptable Model (TAM), yang merupakan alat ukur penggunaan aplikasi penjualan yang berkaitan dengan penggunaan aplikasi oleh user yang bersangkutan. Diterapkan di CV Jaya Citra Madani untuk mengetahui sejauh mana alat ukur tersebut dipergunakan untuk mengukur penggunaan aplikasi penjualan oleh user di CV Jaya Citra Madani mengenai user interface program dan kemudahan penggunaan aplikasi. Untuk hasil ukur tersebut akan melakukan revisi dan perbaikan untuk sistem yang digunakan dan dikembangkan agar lebih mudah dioperasikan dan mempercepat kinerja di CV Jaya Citra Madani.

Technology Acceptance Model (TAM) merupakan model penelitian yang paling luas digunakan untuk meneliti adopsi teknologi informasi, dalam kurun waktu 18 tahun terakhir TAM merupakan model yang paling populer dan banyak digunakan dalam berbagai penelitian mengenai proses adopsi dari penggunaan atau penerimaan sistem informasi. Kesederhanaan dan kemampuan menjelaskan hubungan sebab akibat merupakan alasan utama penggunaan TAM. Tujuan penelitian adalah :

1. Mengetahui gambaran tentang kemudahan dalam Desain Antar Muka Aplikasi $\left(\mathrm{X}_{1}\right)$, Penggunaan $\left(\mathrm{X}_{2}\right)$, Sikap Pengguna Terhadap Aplikasi $\left(\mathrm{X}_{3}\right)$, Perilaku Pengguna $\left(\mathrm{X}_{4}\right)$, 
Kondisi Nyata Pengguna $\left(\mathrm{Y}_{1}\right)$ memuat pandangan pengguna Aplikasi Penjualan Sparepart dan Service Komputer di CV Jaya Citra Madani.

2. Mengetahui pengaruh antara Desain Antar Muka Aplikasi $\left(X_{1}\right)$, Penggunaan $\left(X_{2}\right)$, Sikap Pengguna Terhadap Aplikasi $\left(\mathrm{X}_{3}\right)$, Perilaku Pengguna $\left(\mathrm{X}_{4}\right)$, Kondisi Nyata Pengguna $\left(\mathrm{Y}_{1}\right)$ memuat pandangan pengguna Aplikasi Penjualan Sparepart dan Service Komputer di CV Jaya Citra Madani.

\section{TINJAUAN PUSTAKA}

\subsection{Sistem}

Suatu sistem terdiri atas bagian-bagian yang saling mempengaruhi dan bekerjasama untuk mencapai tujuan. Suatu sistem dapat berbentuk abstrak maupun fisik. Sistem abstrak adalah suatu susunan teratur tentang gagasan atau konsepsi yang saling tergantung. Sistem fisik adalah serangkaian unsur yang bekerjasama untuk mencapai tujuan (Jogiyanto, 2010).

\subsection{Sistem Informasi}

Sekumpulan elemen yang bekerja sama dalam melaksanakan pengolahan data yang berupa pengumpulan, penyimpanan dan pemrosesan data untuk menghasilkan informasi yang ada nilainya (Nugroho, Fitriasih, \& Widada, 2015).

\subsection{Metode TAM}

Konsep TAM dikembangkan oleh Davis menurut Ni Luh Nyoman Sherina Devi dan I Wayan Suartana, menawarkan sebuah teori sebagai landasan untuk mempelajari dan memahami perilaku pemakai dalam menerima dan menggunakan sistem informasi (Irawan \& Mafrudhoh, 2017).

Menurut Lambertus Fatmasari dan Muhammad Ariadi dalam Jurnal metode TAM, salah satu teori tentang penggunaan sistem teknologi informasi yang dianggap sangat berpengaruh dan umumnya digunakan untuk menjelaskan penerimaan individual terhadap penggunaan sistem teknologi informasi adalah model penerimaan teknologi (Ariadi \& Fatmawati, 2014).

\subsection{Referensi Jurnal terkait}

Jurnal referensi merupakan acuan penulis dalam membuat karya ilmiah berdasarkan jurnal yang sudah ada, meliputi sebagai berikut :

a. Menurut jurnal dari Lisa N Noor dengan judul Analisis Faktor-Faktor Penerimaan Penggunaan QUIPPERSCHOOL.COM Dengan Menggunakan Pendekatan Technology Acceptance Model (TAM) dan Theory Of Planned Behavior (TPB) di SMA NEGERI 7 YOGYAKARTA. Hasil penelitian bahwa Konstruk PEOU mempengaruhi konstruk PU; Konstruk PU mempengaruhi konstruk ATU; Konstruk PEOU tidak memiliki pengaruh terhadap konstruk ATU; Konstruk PU tidak memiliki pengaruh terhadap konstruk BIUS; Konstruk ATU mempengaruhi konstruk BIUS; Konstruk SN tidak memiliki pengaruh terhadap konstruk BIUS; dan Konstruk PBC mempengaruhi konstruk BIUS. Selain itu koefisien variabel laten PU terhadap ATU memiliki nilai paling besar diantara nilai koefisien variabel laten pada model hubungan antar konstruk lainnya (Noor, 2015).

b. Menurut jurnal dari Fatmasari dan Muhammad Ariadi dengan jurnal yang berjudul Penerapan metode Techonolgy Acceptance Model terhadap Penerimaan KRS Online. Dalam penelitian tersebut menggunakan variabel Perceived ease of use (PEU), Perceived usefulness (PU), Behavioral intention of use (BITU), respondennya adalah 
mahasiswa ilmu komputer Universitas Bina Darma Palembang. Hasil penelitian menyatakan bahwa kebermanfaatan (PEU) pada sistem KRS Online terhadap penerimaan penggunanya dapat diterima dan kemudahan dari sistem (PU) KRS Online berpengaruh terhadap penerimaan penggunanya dapat diterima (Ariadi \& Fatmawati, 2014).

\section{III.METODE PENELITIAN}

\subsection{Jenis dan Pendekatan Penelitian}

Metode yang digunakan dalam penelitian ini merupakan penelitian kualitas, yaitu penelitian yang bertujuan untuk mengetahui hubungan sebab-akibat dari variabelvariabel yang diteliti untuk menjawab pertanyaan penelitian. Jenis penelitian ini proporsional stratifed random sampling (Kaster \& Boediono, 2008).

\subsection{Metode Pengumpulan Data}

\section{Sumber Data}

a. Data Primer yaitu data yang diambil langsung, tanpa perantara, dari sumbernya. Dalam hal ini peneliti dapat memperoleh data yang langsung ditemui dilapangan dalam hal ini user yang aktif menggunakan aplikasi penjualan dan service di CV Jaya Citra Madani.

b. Data Sekunder yaitu data yang diambil secara tidak langsung dari sumbernya bersumber dari kepustakaan, yang diteliti dari literatur-literatur, buku-buku, dokumen dan artikel yang berkaitan dengan masalah yang diteliti.

2. Teknik Pengumpulan Data

Teknik pengumpilan data dalam penelitian ini menggunakan tiga cara, yaitu penelitian pustaka, penelitian lapangan dan kuesioner.

c. Teknik Kepustakaan (Library Research)

Kepustakaan dengan mengambil materi dan jurnal mengenai metode TAM dimana jurnal acuan adalah jurnal dari Lisa N Noor, Dedi Irawan dan Nurlaeili, Fatmasari dan Muhammad Ariadi mengenai analisa penggunaan Metode TAM dalam analisa masalah dan buku mengenai metode TAM..

d. Penelitian Lapangan (Field Research)

Data utama penelitian ini diperoleh melalui penelitian lapangan, peneliti ini memperoleh data langsung dari pihak pertama (data primer). Pada penelitian ini, yang menjadi subyek penelitian adalah petugas dan pegawai di CV Jaya Citra Madani.

e. Kuisioner

Kuisioner dengan meminta jawaban dari responden disini Karyawan CV Jaya Citra Madani. Adapun jumlah responden yang akan menjadi sample penelitian sebanyak 50 orang yang tersebar pada bagian penjualan, bagian pembelian, teknisi, kepala toko, pimpinan dan juga sebagian pelanggan.

\subsection{Hipotesis yang dikembangkan}

Adapun hipotesis yang dikembangkan dalam penelitian ini adalah :

1. Pengaruh Desain Antar Muka terhadap Kondisi Nyata Pengguna $\left(\mathrm{H}_{1}\right)$. Desain antar muka aplikasi menjadi tolak ukur dalam penggunaan aplikasi dimana setiap pengguna akan melihat sisi balik dari aplikasi dimana memudahkan dan nyaman dalam penggunaan aplikasi tersebut, dikategorikan dalam 3 point mudah, cukup mudah, susah digunakan. 
2. Pengaruh Penggunaan Aplikasi terhadap kondisi nyata pengguna $\left(\mathrm{H}_{2}\right)$. Pengaruh penggunaan aplikasi secara mental akan berpengaruh dalam kinerja sehari-hari, dimana setiap pengguna yang menggunakan aplikasi apakah ada keluhan secara fisik seperti mata lelah apabila terlalu lama menunggu loading sistem dan sebagainya.

3. Pengaruh sikap pengguna terhadap kondisi nyata pengguna aplikasi $\left(\mathrm{H}_{3}\right)$. Sikap pengguna aplikasi menjadi tolak ukur dimana kondisi nyata pengguna aplikasi dalam menggunakan aplikasi tersebut apakah berpengaruh dalam emosi atau tidak, sehingga secara konseptual aplikasi bisa berjalan normal tanpa mengganggu kondisi pengguna aplikasi.

4. Pengaruh Perilaku Pengguna dengan Kondisi Nyata Pengguna Aplikasi $\left(\mathrm{H}_{4}\right)$. Perilaku sehari-hari pengguna menjadi salah satu tolak ukut kondisi nyata pengguna aplikasi, apakah perilaku baik atau buruk pengguna berpengaruh terhadap aplikasi apakah akan merugikan atau menguntungkan.

\section{HASIL DAN PEMBAHASAN}

\subsection{Pembahasan Metode TAM}

Penelitian mengambil lokasi di CV Jaya Citra Madani, salah satu Unit usaha penjualan sparepart komputer yang berada di daerah Surakarta dan sekitarnya, yang merupakan pusat penjualan sparepart komputer memerlukan penggunaan sistem informasi berbasis teknologi untuk menunjang aktivitas operasionalnya agar efektif dan efisien.

Populasi yang diambil sampel adalah seluruh karyawan yang bekerja di CV Jaya Citra Madani yang menggunakan maupun berhubungan dengan sistem informasi. Metode penentuan sampel dilakukan dengan metode nonprobability sampling, melalui teknik purposive sampling. Diambil sampel para karyawan yang menggunakan maupun berhubungan dengan sistem informasi dalam pekerjaannya.

Instrumen penelitian yang akan digunakan pada penelitian ini disusun berdasarkan adaptasi item-item kuesioner yang sudah digunakan pada penelitian-penelitian sebelumnya. Hal ini dilakukan karena konstruk-konstruk penelitian kali ini merupakan konstruk-konstruk dari teori TAM yang sudah lama dikembangkan. Adaptasi item-item kuesioner dilakukan guna memperoleh validitas item-item penyusun konstruk penelitian (construct validity). Kriteria ukuran refleksif individual dikatakan tinggi jika berkorelasi lebih besar dari 0,70 dengan konstruk yang diukur. Tetapi, loading factor 0,50 sampai 0,60 masih dapat dipertahankan untuk model yang masih dalam tahap pengembangan.

Penyusunan kuesioner penelitian berdasarkan adaptasi item-item tersebut selanjutnya disesuaikan dengan tujuan penelitian. Objek (sistem) disesuaikan dengan menggunakan sistem penjualan d CV Jaya Citra Madani setelah menentukan item-item asli selanjutnya item-item tersebut.

Item yang digunakan dalam kuesioner sejumlah 27 item yang tersusun atas 5 konstruk. Masing-masing konstruk terdiri dari Konstruk Penggunaan $=5$ item, Konstruk Desain Antar Muka $=10$ item, Konstruk Sikap Pengguna Terhadap Aplikasi $=5$ item. Konstruk Perilaku Pengguna $=5$ Item, Kondisi Nyata Penggunaan $=2$ Item .

Skala pengukuran setiap alternative jawaban menggunaka skala Likert yang merupakan skala yang biasa digunakan untuk mengukur sikap, pendapat, dan persepsi seseorang. Pada penelitian ini, pengukuran terhadap pertanyaan-pertanyaan menggunakan skala Likert 4 poin. Skala Likert 4 poin merupakan skala tingkat kesetujuan terhadap pertanyaan yang menjadi indikator dengan rentang skala 1: Sangat Tidak Setuju, 2: Tidak Setuju, 3: Setuju, 4: Sangat Setuju. Dalam penelitian ini, skala bernilai netral atau kategori tengah ditiadakan dengan maksud menghindari pendapat netral atau bias. Skor skala yang menyediakan kategori tengah dengan yang tidak memiliki kategori tengah, tidak memiliki perbedaan yang berarti, dimana reliabilitas pengukuran dan validitas butir tidak mengalami perbedaan, yang berbeda adalah varian skor. 


\subsection{Profil Responden}

Subyek pada penelitian ini adalah mahasiswa pengguna Aplikasi Penjualan pada CV Jaya Citra Madani. Sumber data yang diperoleh yaitu melalui penyebaran kuesioner yang dimulai pada tanggal 01 Maret 2017 sampai dengan tanggal 31 Maret 2017. Kuesioner ini ditujukan untuk petugas di CV Jaya Citra Madani yang aktif menggunakan aplikasi di tahun 2017. Berdasarkan kuesioner yang dibagikan sebanyak 50 responden, 40 kuesioner yang diisi lengkap dan bisa diolah selanjutnya dalam analisa statistik. Adapun hasil dari masing-masing konstruk seperti Tabel 1 berikut :

Tabel 1. Statistik deskriptif data masing-masing konstruk

\begin{tabular}{|l|r|r|r|r|r|c|}
\hline \multicolumn{1}{|c|}{ Pertanyaan } & \multicolumn{1}{c|}{ N } & Minimum & Maksimum & \multicolumn{1}{c|}{ sum } & \multicolumn{1}{c|}{ Mean } & $\begin{array}{c}\text { Std. } \\
\text { Deviation }\end{array}$ \\
\hline Penggunaan & 40 & 118 & 126 & 613 & 122,6 & 2,880972058 \\
\hline Desain Antar Muka & 40 & 94 & 141 & 1157 & 115,7 & 13,57325802 \\
\hline $\begin{array}{l}\text { Sikap Pengguna } \\
\text { Terhadap Aplikasi }\end{array}$ & 40 & 107 & 122 & 574 & 114,8 & 6,457553716 \\
\hline Perilaku Pengguna & 40 & 107 & 121 & 576 & 115,2 & 5,674504384 \\
\hline Valid N & 40 & & & & & \\
\hline
\end{tabular}

Penjelasan dari statistik deskriptif setiap variabel Tabel 1. adalah sebagai berikut:

1. Konstruk Penggunaan

Data konstruk penggunaan diperoleh dari penyebaran kuesioner tertutup dengan jumlah pernyataan sebanyak 5 item/butir dengan menggunakan skala pilihan jawaban 5 skala ( 5 alternatif jawaban), mempunyai skor teoritik antara skor terendah 118 sampai skor tertinggi 126. Skor empirik menyebar dari skor terendah 118 sampai skor tertinggi 126, dengan skor total yaitu 613, rata-rata (Mean) 122,6, dan simpangan baku 2,88.

2. Konstruk Desain Antar Muka

Data konstruk desain antar muka diperoleh dari penyebaran kuesioner tertutup dengan jumlah pernyataan sebanyak 10 item/butir dengan menggunakan skala pilihan jawaban 5 skala (5 alternatif jawaban), mempunyai skor teoritik antara skor terendah 94 sampai skor tertinggi 141. Skor empirik menyebar dari skor terendah 91 sampai skor tertinggi 141, dengan skor total yaitu 1157, rata-rata (Mean) 115,7, dan simpangan baku 13,57.

3. Konstruk Sikap Pengguna Terhadap Aplikasi

Data konstruk desain antar muka diperoleh dari penyebaran kuesioner tertutup dengan jumlah pernyataan sebanyak 5 item/butir dengan menggunakan skala pilihan jawaban 5 skala (5 alternatif jawaban), mempunyai skor teoritik antara skor terendah 107 sampai skor tertinggi 122. Skor empirik menyebar dari skor terendah 107 sampai skor tertinggi 122, dengan skor total yaitu 574, rata-rata (Mean) 114,8, dan simpangan baku 6,45.

4. Konstruk Perilaku Pengguna

Data konstruk desain antar muka diperoleh dari penyebaran kuesioner tertutup dengan jumlah pernyataan sebanyak 5 item/butir dengan menggunakan skala pilihan jawaban 5 skala (5 alternatif jawaban), mempunyai skor teoritik antara skor terendah 107 sampai skor tertinggi 121. Skor empirik menyebar dari skor terendah 107 sampai skor tertinggi 121, dengan skor total yaitu 576, rata-rata (Mean) 115,2, dan simpangan baku 5,67.

\subsection{Pengujian Persyaratan Analisis}

1. Perancangan Inner Model

Perancangan inner model hubungan antar konstruk didasarkan analisa penerapan aplikasi penjualan dan service komputer pada CV Jaya Citra Madani dengan Metode 
Technologi Acceptable Model (TAM). Adapun perancangan inner model dapat terlihat pada Gambar 1.

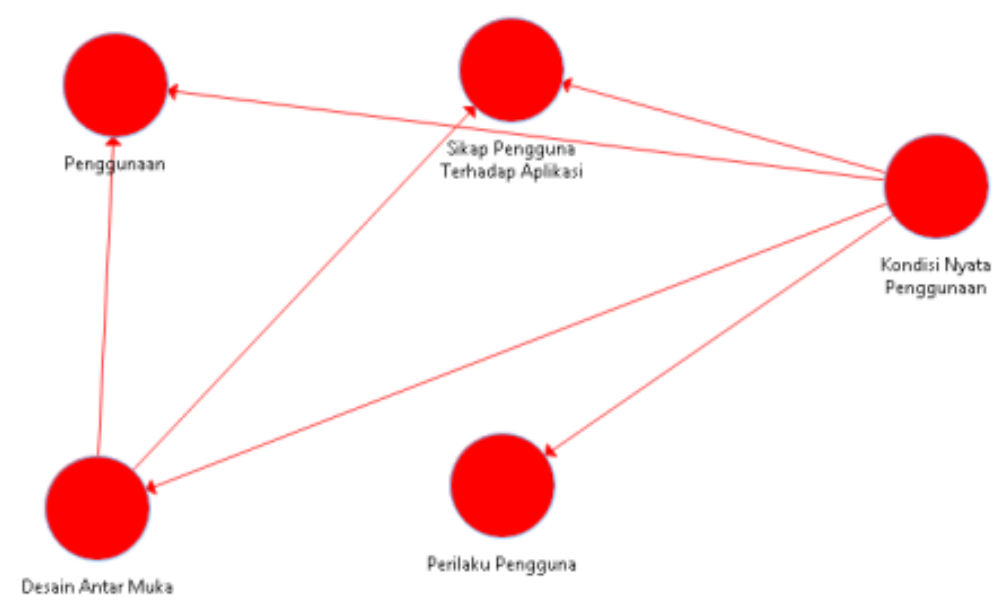

Gambar 1. Perancangan Inner Model

2. Perancangan Outer Model

Indikator dari masing-masing konstruk yaitu konstruk Penggunaan, Desain Antar Muka, Sikap Pengguna Terhadap Aplikasi, Perilaku Pengguna dan Kondisi Nyata Penggunaan pada outer model bersifat refleksif. Sehingga arah panah pada model pengukuran dari arah konstruk menuju indikator. Hubungan antar indicator tersebut dapat dilihat pada Gambar 2.

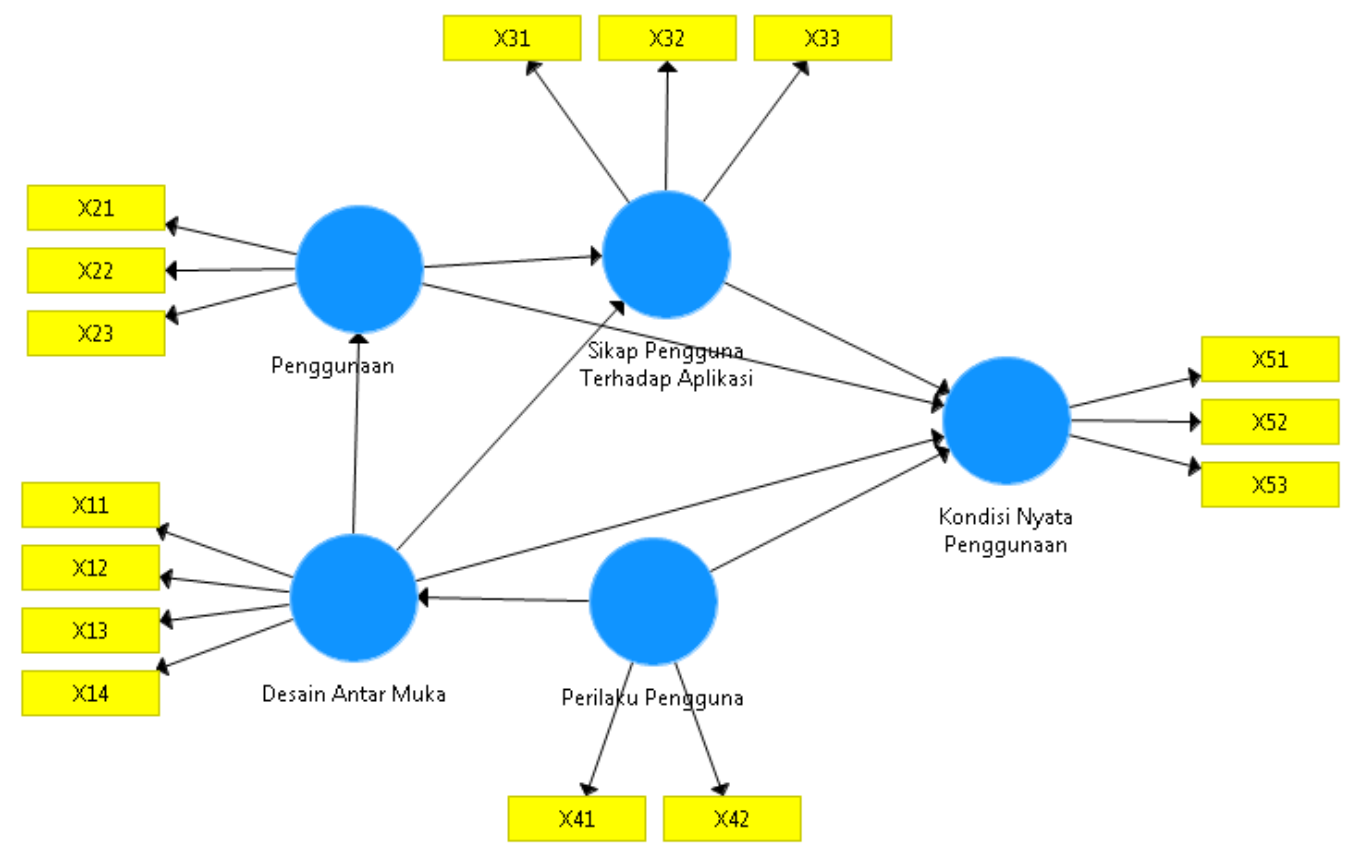

Gambar 2. Konstruk Indikator

\section{Estimasi Model}

Metode pendugaan parameter (estimasi) di dalam penelitian. Ketentuan untuk menguji unidimensionalitas dari masing-masing konstruk dengan melihat convergent validity dari masing-masing indikator konstruk. 
Berdasarkan hasil estimasi model yang digunakan masing-masing indicator memiliki loading factor $>0,50$ sehingga dapat dilakukan suatu evaluasi, hasil tersebut dapat dilihat dalam Gambar 3.

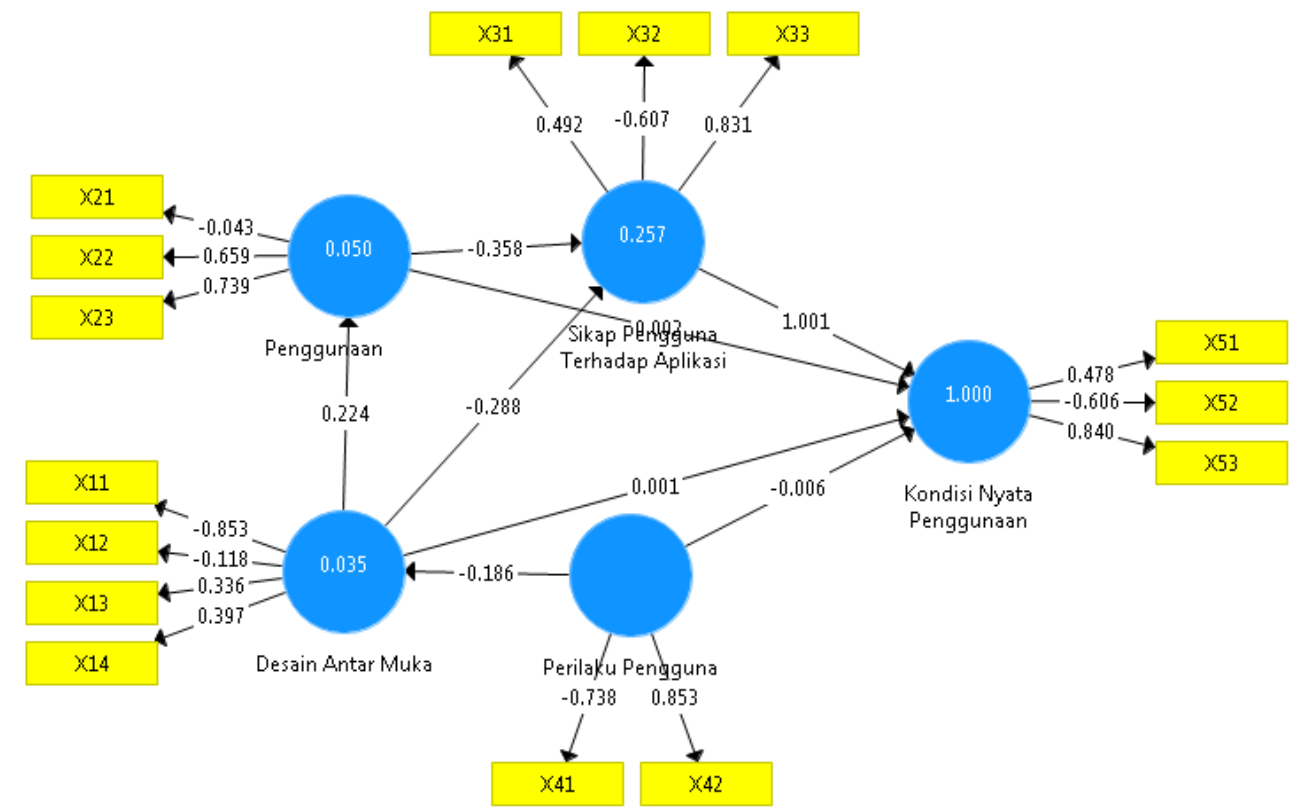

Gambar 3. Hasil Eksekusi Model

4. Pengujian outer model

Terdapat 3 kriteria untuk mengevaluasi outer model dengan indikator refleksif yaitu convergent validity, discriminant validity, dan composite reliability. Convergent validity dari measurement model dengan indikator refleksif dapat dilihat dari korelasi antara skor item/indikator dengan konstruknya (loading factor) yang dapat dilihat dari output outer loadings. Adapun Output outer loadings dari hasil estimasi PLS Algorithm dapat dilihat pada Tabel 2.

Tabel 2. Output Outer Loading

\begin{tabular}{|c|c|c|c|c|c|}
\hline & $\begin{array}{c}\text { Desain } \\
\text { Antar Muka }\end{array}$ & $\begin{array}{l}\text { Kondisi Nyata } \\
\text { Penggunaan }\end{array}$ & Penggunaan & $\begin{array}{c}\text { Perilaku } \\
\text { Pengguna }\end{array}$ & $\begin{array}{c}\text { Perilaku } \\
\text { Pengguna }\end{array}$ \\
\hline X11 & $-0,853$ & & & & \\
\hline X12 & $-0,118$ & & & & \\
\hline X13 & 0,336 & & & & \\
\hline X14 & 0,397 & & & & \\
\hline $\mathrm{X} 21$ & & & $-0,043$ & & \\
\hline $\mathrm{X} 22$ & & & 0,659 & & \\
\hline $\mathbf{X 2 3}$ & & & 0,739 & & \\
\hline $\mathbf{X 3 1}$ & & & & & 0,492 \\
\hline X32 & & & & & $-0,607$ \\
\hline $\mathbf{X 3 3}$ & & & & & 0,831 \\
\hline $\mathrm{X41}$ & & & & $-0,738$ & \\
\hline $\mathrm{X42}$ & & & & 0,853 & \\
\hline X51 & & 0,478 & & & \\
\hline $\mathbf{X 5 2}$ & & $-0,606$ & & & \\
\hline X53 & & 0,840 & & & \\
\hline
\end{tabular}


Berdasarkan pada output outer loadings dapat dilihat bahwa hasil loading factor semua indikator untuk masing-masing konstruk sudah memenuhi convergent validity, karena semua nilai loading factor setiap indikator sudah di atas 0,50 .

\subsection{Pembahasan Hasil Penelitian}

1. Pengaruh Desain Antar Muka Terhadap Kondisi Nyata Pengguna (H1)

Pengujian path coefficients desain antar muka terhadap penggunaan dapat dilihat pada Tabel 3. Hasil pengujian dengan menggunakan SEM berikut :

Tabel 3. path coefficients desain antar muka terhadap penggunaan

\begin{tabular}{|l|r|r|}
\hline & T Statistics \\
& Original Sample (O) & \multicolumn{1}{|c|}{\begin{tabular}{c} 
(|O/STDEV|) \\
\hline Desain Antar Muka -> Penggunaan
\end{tabular}} \\
\hline
\end{tabular}

Persepsi desain antar muka yang user interface menjadi faktor yang mempengaruhi sikap pengguna terhadap aplikasi yang digunakan. Hal tersebut berarti kemudahan dalam menggunakan sistem dengan user interface mempengaruhi penggunaan dalam bekerja menggunakan sistem yang berjalan di CV Jaya Citra Madani. Berdasarkan pengujian hipotesis pertama diketahui bahwa $\mathrm{H} 1$ yang diajukan dapat diterima. Hipotesa ini dilihat dari nilai eksekusi model bahwa nilai Outputpath coefficients menunjukkan bahwa nilai t statistik untuk konstruk desain antar muka terhadap konstruk penggunaan lebih besar dari 0,05 yaitu 0,644 bahwa menunjukkan ada pengaruh desain antar muka terhadap penggunaan.

2. Pengaruh Penggunaan Apikasi terhadap Kondisi Nyata Pengguna (H2)

Pengujian path coefficients pengguna aplikasi terhadap kondisi nyata pengguna dapat dilihat pada Tabel 4. Hasil pengujian dengan menggunakan SEM berikut :

Tabel 4. Path Coefficients Penggunaan terhadap Kondisi Nyata Pengguna

\begin{tabular}{|l|c|ll|}
\hline & Original Sample (O) & $\begin{array}{l}\text { T Statistics } \\
(\mid \mathbf{O} / \text { STDEV })\end{array}$ & \\
\hline Penggunaan -> Kondisi Nyata Pengguna & $-0,002$ & & 0,038 \\
\hline
\end{tabular}

Berdasarkan pengujian hipotesis pertama diketahui bahwa $\mathrm{H} 2$ yang diajukan tidak dapat diterima. Outputpath coefficients menunjukkan bahwa nilai t statistik untuk konstruk penggunaan terhadap kondisi nyata pengguna tidak lebih besar dari 0,05 yaitu $-0,002$ bahwa menunjukkan tidak ada pengaruh penggunaan terhadap kondisi nyata pengguna. Persepsi penggunaan aplikasi dengan kondisi nyata pengguna ternyata tidak berdampak positif, karena kondisi nyata pengguna lebih sedikit menggunakan aplikasi yang digunakan di CV Jaya Citra Madani. User lebih sering menggunakan aplikasi pada saat melakukan transaksi saja.

3. Pengaruh Sikap Pengguna Terhadap Kodisi Nyata Pengguna Apikasi (H3).

Pengujian path coefficients sikap pengguna terhadap kondisi nyata pengguna aplikasi dapat dilihat pada Tabel 5. Hasil pengujian dengan menggunakan SEM berikut :

Tabel 5. path coefficients sikap pengguna terhadap kondisi nyata pengguna aplikasi

\begin{tabular}{|l|r|r|}
\hline & & \multicolumn{2}{|l|}{ T Statistics } \\
& Original Sample (O) & $(\mid \mathbf{O} /$ STDEV $)$ \\
\hline Penggunaan -> Sikap Pengguna Terhadap Aplikasi & $-0,444$ & 1,065 \\
\hline
\end{tabular}

Berdasarkan pengujian hipotesis pertama diketahui bahwa H3 yang diajukan tidak dapat diterima. Outputpath coefficients menunjukkan bahwa nilai t statistik untuk konstruk penggunaan terhadap sikap pengguna terhadap aplikasi tidak lebih besar dari 
0,05 yaitu -0.444 bahwa menunjukkan tidak ada pengaruh penggunaan terhadap sikap pengguna terhadap aplikasi. Persepsi penggunaan aplikasi akan merubah mindset dari user dalam menggunakan aplikasi ternyata tidak mempengauhi dalam penggunaan aplikasi. Sikap pengguna terhadap aplikasi tergantung bagiamana setiap user menyikapi penggunaan aplikasi tersebut sesuai kebutuhan.

4. Pengaruh Perilaku Pengguna dengan Kondisi Nyata Pengguna Aplikasi (H4)

Pengujian path coefficients pengaruh perilaku pengguna dengan kondisi nyata pengguna aplikasi dapat dilihat pada Tabel 6 . Hasil pengujian dengan menggunakan SEM berikut :

Tabel 6. path pengaruh perilaku pengguna dengan kondisi nyata pengguna aplikasi

\begin{tabular}{|l|r|r|}
\hline & Original Sample (O) & $\begin{array}{l}\text { T Statistics } \\
(\mid \mathbf{O} / \mathbf{S T D E V})\end{array}$ \\
\hline Perilaku Pengguna -> Kondisi Nyata Pengguna & 0,985 & 3,389 \\
\hline
\end{tabular}

Berdasarkan pengujian hipotesis pertama diketahui bahwa $\mathrm{H} 4$ yang diajukan dapat diterima. Outputpath coefficients menunjukkan bahwa nilai t statistik untuk konstruk perilaku pengguna terhadap kondisi nyata pengguna aplikasi lebih besar dari 0,05 yaitu 0.985 bahwa menunjukkan ada pengaruh perilaku pengguna terhadap kondisi nyata pengguna aplikasi. Perilaku pengguna terhadap kondisi nyata pengguna dalam melakukan aktifitasnya menggunakan aplikasi penjualan di CV Jaya Citra Madani ternyata mempunyai pengaruh besar. Dimana apabila perilaku pengguna aplikasi baik maka dalam kondisi nyata pekerjaannya pun akan menjadi baik.

\section{KESIMPULAN DAN SARAN}

\subsection{Kesimpulan}

1. Pengaruh desain antar muka terhadap kondisi nyata pengguna aplikasi menunjukkan bahwa nilai $t$ statistik untuk konstruk desain antar muka terhadap kondisi nyata pengguna aplikasi lebih besar dari 0,05 yaitu 0,644 bahwa menunjukkan ada pengaruh desain antar muka terhadap kondisi nyata pengguna aplikasi. lebih besar dari 0,644.

2. Pengaruh penggunaan aplikasi terhadap kondisi nyata pengguna nilai t statistik untuk konstruk penggunaan terhadap kondisi nyata pengguna tidak lebih besar dari 0,05 yaitu $-0,002$ bahwa menunjukkan tidak ada pengaruh penggunaan terhadap kondisi nyata pengguna.

3. Pengaruh sikap terhadap kondisi nyata pengguna aplikasi menunjukkan bahwa nilai $t$ statistik untuk konstruk penggunaan terhadap sikap pengguna terhadap aplikasi tidak lebih besar dari 0,05 yaitu $-0,444$ bahwa menunjukkan tidak ada pengaruh penggunaan terhadap sikap pengguna terhadap aplikasi.

4. Pengaruh perilaku pengguna terhadap kondisi nyata pengguna aplikasi menunjukkan bahwa nilai $\mathrm{t}$ statistik untuk konstruk perilaku pengguna terhadap kondisi nyata pengguna aplikasi lebih besar dari 0,05 yaitu 0,985 bahwa menunjukkan ada pengaruh perilaku pengguna terhadap kondisi nyata pengguna aplikasi.

\subsection{Saran}

Menambahkan variabel-variabel eksternal di luar variabel asli yang terdapat dalam model Technology Acceptance Model (TAM) guna dapat menjelaskan lebih lanjut mengenai faktor-faktor lain yang mempengaruhi pengguna dalam menggunakan sistem dikarenakan pada penelitian ini variabel yang digunakan masih terbatas pada variabel-variabel asli TAM. 


\section{DAFTAR PUSTAKA}

Ariadi, M., \& Fatmawati. (2014). Penerapan metode TAM terhadap penerimaan KRS Online. MATRIK, 16, 1-9.

Irawan, D., \& Mafrudhoh, N. (2017). Analisis sistem pendukung keputusan untuk pemberian keputusan pembebasan biaya bagi siswa yang kurang mampu menggunakan metode simple additive weighting. Jurnal TAM, 7, 27-37.

Jogiyanto. (2010). Sistem Teknologi Informasi. Jogjakarta: Andi Offset.

Kaster, W., \& Boediono. (2008). Teori dan Aplikasi Statistika dan Probabilitas . Bandung: Rosda.

Noor, L. N. (2015). Analisis Faktor-faktor Penerimaan Penggunaan QUIPPERSCHOOL.COM Dengan Menggunakan Pendekatan Technology Acceptance Model (TAM) dan Theory Of Planned Behavior (TPB) di SMA Negeri \& Yogyakarta. Yogyakarta: Universitas Negeri Yogyakarta.

Nugroho, B., Fitriasih, S. H., \& Widada, B. (2015). Sistem Informasi Rekam Medis di Puskesmas Masaran I Sragen. Tikomsin , 49 - 56. 